\title{
POTENCIAL ALELOPÁTICO DE Merostachys multiramea HACKEL SOBRE A GERMINAÇÃO DE Araucaria angustifolia (BERT.) KUNTZE
}

\author{
Allelopathic Potential of Merostachys multiramea Hackel in Araucaria \\ angustifolia (Bert.) Kuntze Germination
}

\author{
Lucila de Almeida Vasques Fernandes \\ Acadêmica do Curso de Engenharia Florestal, UFPR, Laboratório de Inventário Florestal, \\ Jardim Botânico - Curitiba - PR. e-mail: lucilavf@yahoo.com.br \\ Dirceu Lúcio Carneiro de Miranda \\ Eng. Florestal, Mestrando em Ciências Florestais, UFPR, Laboratório de Inventário Florestal, \\ Jardim Botânico - Curitiba - PR. e-mail: mirandaufpr@yahoo.com.br \\ Carlos Roberto Sanquetta \\ Eng. Florestal, M.Sc., Ph.D., Professor do Departamento de Ciências Florestais, UFPR, Laboratório de Inventário Florestal, \\ Jardim Botânico - Curitiba - PR. e-mail: sanquetta@ufpr.br
}

\begin{abstract}
Resumo
Em regiões de Floresta Ombrófila Mista, a ocorrência de taquaras é comum e, devido ao seu forte poder competitivo e de propagação, podem interferir diretamente nos processos de regeneração e no estabelecimento de outras espécies da floresta. Um dos motivos que pode explicar esta influência é a alelopatia. O objetivo deste trabalho foi verificar se há influência alelopática de Merostachys multiramea Hackel (taquara-comum ou taquara-lixa) sobre a germinação de sementes de Arancaria angustifolia (Bert.) Kuntze. Visando a atender a esse objetivo, promoveu-se o teste de germinação das sementes de Araucaria angustifolia (Bert.) Kuntze sob efeito de diferentes tratamentos, com concentrações de extrato de taquara a $0 \%, 2,5 \%, 5 \%$ e $10 \%$. A partir dos resultados da contagem das sementes germinadas, calculou-se a porcentagem de germinação e o índice de velocidade de germinação (IVG). Verificou-se, por meio de análise estatística, via ANOVA, que não houve diferenças estatísticas significativas a uma probabilidade de $95 \%$ para essas duas variáveis. Porém, em termos numéricos, os tratamentos mostraram resultados satisfatórios para porcentagem de germinação média (T1, 86\%; T4, 83; T2, 79; T3, 77). O T4 foi o que apresentou maior valor médio de IVG, com 1,1556, sendo que os tratamentos T1, T3 e T2 resultaram em valores de 1,1261; 1,1126 e 0,9268, respectivamente. Com o presente estudo, pôde-se concluir que os tratamentos não inibiram a germinação dessa espécie, embora tenha havido diferença numérica entre eles.
\end{abstract}

Palavras-chave: Alelopatia; Araucaria angustifólia; Taquara; Teste de germinação. 


\begin{abstract}
The occurrence of taquara bamboo is common in Araucaria forest areas, and due to its strong competitive potential and propagation, it can interfere directly in the regeneration processes and in the establishment of other forest species. One reason that can explain this influence is the allelopathy. The objective of this work was to verify the allelopathic influence of Merostachys multiramea Hackel (common taquara or taquara-lixa) on germination of Araucaria angustifolia (Bert.) Kuntze seeds. In order to reach this objective, a germination test was carried out under the effect of different treatments with taquara extract concentrations $(0 \%, 2.5 \%, 5 \%$ and $10 \%)$. The germination percentage and speed germination index (IVG) were calculated. It was verified, after application of ANOVA, that there were no significant statistical differences among the treatment means for these two variables, at $95 \%$ of probability. However, the treatments had shown satisfactory results for average percentage of germination (T1,86\%; T4, 83; T2, 79; T3, 77). The T4 resulted in the largest average IVG with 1.1556, and the treatments T1, T3 and T2 resulted in 1.1261, 1.1126 and 0.9268, respectively. It was concluded that the treatments did not inhibit the germination of araucaria, although it has had numeric difference among them.
\end{abstract}

Keywords: Allelopathy; Araucaria angustifolia; Bamboo; Test of germination.

\title{
INTRODUÇÃO
}

A Floresta Ombrófila Mista, também conhecida como Floresta de Araucária, foi e continua sendo altamente antropizada. De uma superfície que compreendia cerca de 37\% para Maack (1968), $40 \%$ para Carvalho (2003) da área do Estado do Paraná $\left(200.000 \mathrm{~km}^{2}\right)$, atualmente a floresta com araucária, de acordo com Castella e Britez (2004), em levantamento realizado pela Fundação de Pesquisas Florestais do Paraná - FUPEF, apenas 0,8\% de sua superfície original (cerca de $1.600 \mathrm{~km}^{2}$ ) encontra-se em estágio avançado de regeneração, com elevada biodiversidade. Entretanto, ainda existem no Paraná mais de 2,5 milhões de hectares de florestas em estágios inicial e médio de regeneração, conforme os critérios do CONAMA.

Esta interferência do homem favoreceu a abertura de clareiras na floresta, que muitas vezes são ocupadas pela presença da taquara-comum ou taquara-lixa (Merostachys multiramea Hackel). Lima (2003); Maack (1968) já evidenciava a abundante presença de taquaras nas florestas paranaenses, ocupando espaços e buscando recursos para sua sobrevivência. Dentre as espécies mais importantes, destacam-se aquelas pertencentes aos gêneros Merostachys e Chusquea.

Conforme Sanquetta et al. (2005), a forte presença competitiva das taquaras no subdossel da floresta pode inibir os processos demográficos das populações arbóreas e conseqüentemente da comunidade como um todo, devido à competitividade que elas ocasionam. Segundo Guilherme (1999), os bambus podem interferir efetivamente no estabelecimento de indivíduos arbóreos e na sua sobrevivência.

Esta intervenção pode ocorrer por duas formas distintas de interferência de uma planta sobre a outra: alelopatia e/ ou competição. Rice (1974), citado por Ferreira e Aquila (2000), afirma que alelopatia depende da liberação de compostos químicos de uma planta no ambiente, enquanto que competição envolve remoção ou redução ambiental (água, luz, nutrientes, etc.).

Alelopatia trata-se da influência positiva ou negativa que uma espécie vegetal pode exercer sobre a outra, por meio da liberação no ambiente, de substâncias químicas produzidas pelo metabolismo secundário da planta.

Conforme Rizvi et al. (1992), citado por Ferreira e Aquila (2000), alelopatia refere-se à influência benéfica ou maléfica de um indivíduo sobre o outro devido à produção de biomoléculas, denominadas aleloquímicos, por uma planta que é lançada no ambiente, seja na fase aquosa do solo ou substrato, seja por substâncias gasosas volatilizadas no ar. 
Existem vários conceitos para definir alelopatia e, segundo Medeiros (1990), citado por PiñaRodrigues e Lopes (2001), esse termo foi criado em 1937, com a junção das palavras gregas alléton (mútuo) e pathos (prejuízo) e refere-se à capacidade que as plantas têm de interferir na germinação e desenvolvimento de outras, por meio de substâncias que são liberadas na atmosfera ou no solo.

Todas as plantas produzem metabólitos secundários, que diferem em qualidade e quantidade de espécies para espécie, assim como diferem em quantidade de um local de ocorrência ou ciclo de cultivo para outro. As plantas também se diferem entre as espécies quanto à tolerância e resistência aos metabólitos secundários, sendo umas mais sensíveis que as outras (FERREIRA; AQUILA, 2000).

O fato de a Floresta Ombrofila Mista ter sofrido forte antropizada tem ocasionado grande prejuízo ao estabelecimento, ao desenvolvimento e à sobrevivência de espécies importantes do ponto de vista conservacionista e de valor econômico, como a araucária. Recuperar e conservar os remanescentes de floresta com araucária é um desafio inatingível somente pelas forças da lei. Reconhecer o possível efeito alelopático que as taquaras podem exercer sobre a germinação e conseqüentemente sobre a regeneração da araucária contribui de forma efetiva para a criação de medidas de restauração e conservação desse ecossistema.

O presente estudo teve o objetivo de verificar se existe influência alelopática da taquara sobre a germinação da Araucaria angustifolia (Bert.) Kuntze, mediante o teste de sua germinação em laboratório, sob influência do extrato preparado com folhas verdes da taquara.

\section{MATERIAIS E MÉTODOS}

O presente estudo consistiu no teste de germinação de sementes da araucária sob efeito de diferentes concentrações do extrato preparado com folhas verdes da taquara.

As folhas da taquara e as sementes da araucária foram coletadas na propriedade da empresa Indústrias Pedro N. Pizzatto Ltda., localizada no município de General Carneiro, no sul do Paraná, o qual apresenta como fitofisionomia vegetal a Floresta Ombrófila Mista.

Após a coleta, foi preparado o extrato, com as folhas ainda verdes, em laboratório, por meio da trituração de $100 \mathrm{~g}$ de folhas em $1000 \mathrm{ml}$ de água, com auxílio de liquidificador doméstico. Com esse procedimento, obteve-se a concentração do extrato $10 \%$.

Para adquirir as concentrações, realizou-se a diluição do extrato 10\%, em água, obtendo os extratos nas concentrações $5 \%$ e $2,5 \%$.

Os tratamentos definidos para o presente trabalho foram as diferentes concentrações do extrato da taquara, apresentando-se da seguinte forma:

T1 = Água - concentração 0,0\% (tratamento testemunha).

$\mathrm{T} 2=$ Extrato de folhas verdes da taquara com concentração $10,0 \%$.

$\mathrm{T} 3=$ Extrato de folhas verdes da taquara com concentração $5,0 \%$.

$\mathrm{T} 4=$ Extrato de folhas verdes da taquara com concentração $2,5 \%$.

O substrato utilizado para a germinação das sementes foi a vermiculita, regada com os respectivos tratamentos, em uma proporção de substrato/líquido de 1:2,5. As sementes foram colocadas no recipiente com vermiculita, de modo que elas ficassem com metade de seu comprimento enterrado.

O delineamento utilizado foi o inteiramente casualizado, onde cada tratamento recebeu 5 repetições, com 20 sementes cada.

As sementes germinadas foram contadas diariamente após um período de 7 dias, usando-se como critério de germinação as sementes que apresentavam radícula com comprimento igual ou superior à metade do tamanho da semente. As sementes germinadas foram visualizadas com a elevação das sementes, sem retirá-las e verificada a germinação por meio da retirada da semente da vermiculita.

A porcentagem de germinação $(G)$ é razão entre o numero de sementes germinadas e o total de sementes. O índice de velocidade de germinação $(I V G)$ é o somatório da razão entre o número de sementes germinadas no tempo $i$ e o espaço de tempo $i$. 
Porcentagem de germinação $(G)$ :

$$
G=\frac{N^{o} \text { de sementes germinadas }}{N^{o} \text { total de sementes }} \cdot 100
$$

Índice de velocidade de germinação (IVG):

$$
I V G=\sum_{i=1}^{n}\left(\frac{n i}{i}\right)
$$

Onde:

$n i=\mathrm{n}^{\mathrm{O}}$ de sementes germinadas no dia $i$

$i=\mathrm{n}^{\mathrm{o}}$ de dias

Foram efetuados o teste de Bartlett para verificar se ocorreu a homogeneidade das variâncias e a análise de variância (ANOVA) para averiguar a existência de diferenças significativas entre as médias.

\section{RESULTADOS E DISCUSSÃO}

De maneira geral, em todas as repetições dos quatro tratamentos, houve um alto valor de germinação das sementes, não apresentando germinação inferior a 50\% do número total de sementes. Pode-se observar que o tratamento 1 foi o que apresentou maior germinação, sendo seguido dos tratamentos 4, 2 e 3. A Tabela 1 mostra o número de sementes que germinaram em cada repetição, assim como o total de germinação em cada tratamento.

TABELA 1 - Número de sementes germinadas em cada repetição e número total de sementes germinadas por tratamento

Table 1 - Number of germinated seeds in each replication and total number of germinated seeds per treatment

\begin{tabular}{ccccc}
\hline & \multicolumn{3}{c}{ Tratamentos } & 3 \\
Repetições & 1 & 2 & 16 & 4 \\
\hline 1 & 16 & 18 & 15 & 16 \\
2 & 17 & 18 & 16 & 18 \\
3 & 19 & 19 & 14 & 15 \\
4 & 18 & 14 & 16 & 17 \\
5 & 16 & 10 & 77 & 83 \\
Total & 86 & 79 & & \\
\hline
\end{tabular}

\section{Porcentagem de germinação (G)}

O tratamento que continha apenas água (T1 - 0\%) apresentou a maior porcentagem de germinação média (86\%) e o Tratamento 3 a menor $(77 \%)$. Ao contrário do que se esperava, o tratamento com maior concentração (T2 - 10\%) não apresentou a menor porcentagem de germinação média, sendo superior ao tratamento $3(5 \%)$. 
De maneira geral, a percentagem de germinação foi alta para todas as parcelas, atingindo $95 \%$ para os tratamentos 1 e 2, na terceira repetição. Entretanto, apenas 50\% das sementes germinaram na quinta repetição do tratamento 5.

$\mathrm{Na}$ Tabela 2 estão apresentados os valores das porcentagens de sementes germinadas em cada repetição dos tratamentos. As porcentagens de germinação média por tratamento foram significantemente altas (FIGURA 1).

TABELA 2 - Porcentagem de germinação de cada repetição e porcentagem de germinação média dos quatro tratamentos

Table 2 - Germination percentage of each replication and average germination percentage of the four treatments

\begin{tabular}{ccccc}
\hline & \multicolumn{3}{c}{ Tratamentos } & 3 \\
Repetições & 1 & 2 & 80 & 4 \\
\hline 1 & 80 & 90 & 75 & 80 \\
2 & 85 & 90 & 80 & 90 \\
3 & 95 & 95 & 70 & 75 \\
4 & 90 & 70 & 80 & 85 \\
5 & 80 & 50 & 77 & 83 \\
\hline G Média & 86 & 79 & &
\end{tabular}

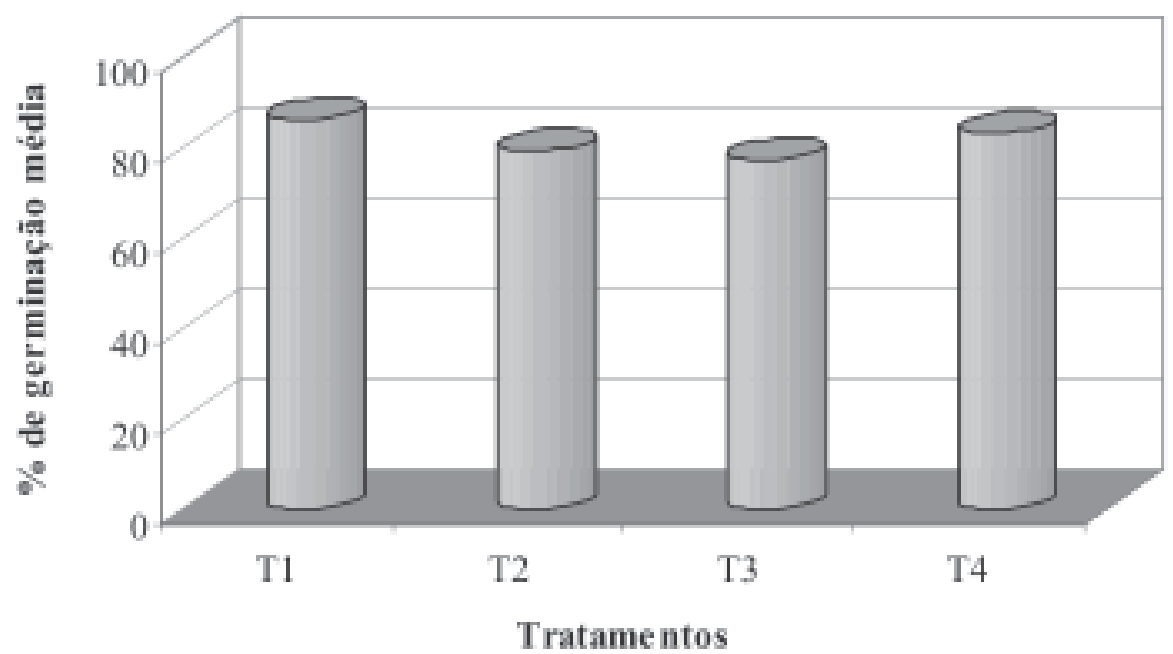

FIGURA 1 - Porcentagem de germinação média de Araucaria angustifolia (Bert.) Kuntze para as diferentes concentrações do extrato de Merostachys multiramea Hackel

Figure 1 - Average germination percentage of Araucaria angustifolia (Bert.) Kuntze seeds for Merostachys multiramea Hackel extract in different concentrations 
A análise de variância mostrou que não houve diferença estatisticamente significativa, a 95\% de probabilidade, na porcentagem de germinação de sementes de Araucaria angustifolia (Bert.) Kuntze, tratadas com diferentes concentrações do extrato de Merostachys multiramea Hackel (TABELA 3).

TABELA 3 - Análise de variância aplicada à porcentagem de germinação

Table 3 - Analysis of variance applied to germination percentage

\begin{tabular}{lccccc}
\hline Fonte de Variaçăo & GL & SQ & QM & F & F critico \\
\hline Tratamentos & 3 & 243,8 & 81,3 & $0,72^{\text {NS }}$ & 3,24 \\
Erro Experimental & 16 & 1800,0 & 112,5 & & \\
\hline Total & 19 & 2043,8 & & & \\
\hline
\end{tabular}

\section{Índice de Velocidade de Germinação (IVG)}

O índice de velocidade de germinação não seguiu a mesma tendência da percentagem de germinação (IVG de T3 = 1,966 e de T2 = 0,601. Pode-se verificar que o tratamento que continha a menor concentração do extrato $(2,5 \%)$ foi o que apresentou germinação mais rápida, mesmo comparada com o tratamento que continha apenas água $(0 \%)$. Pode-se observar, ainda, que tratamento com extrato de maior concentração $(10 \%)$ germinou mais lentamente.

$\mathrm{Na}$ Tabela 4 estão apresentados os valores dos (IVG) em cada repetição dos tratamentos. Também pode ser observado o (IVG) médio por tratamento na Tabela 4 e Figura 2.

TABELA 4 - Índice de velocidade de germinação de cada repetição e índice de velocidade de germinação médio dos quatro tratamentos

Table 4 - Germination speed index for each replication and average germination speed index for the four treatments

\begin{tabular}{ccccc}
\hline & \multicolumn{4}{c}{ Tratamentos } \\
\hline Repetições & 1 & 2 & 3 & 4 \\
1 & 1,0334 & 1,0341 & 1,9666 & 1,1583 \\
2 & 1,2406 & 1,1592 & 1,0504 & 1,1953 \\
3 & 1,2146 & 1,0029 & 0,9146 & 1,0471 \\
4 & 1,0661 & 0,8365 & 0,7968 & 1,3134 \\
5 & 1,0760 & 0,6012 & 0,8344 & 1,0642 \\
\hline IVG Médio & 1,1261 & 0,9268 & 1,1126 & 1,1556 \\
\hline
\end{tabular}




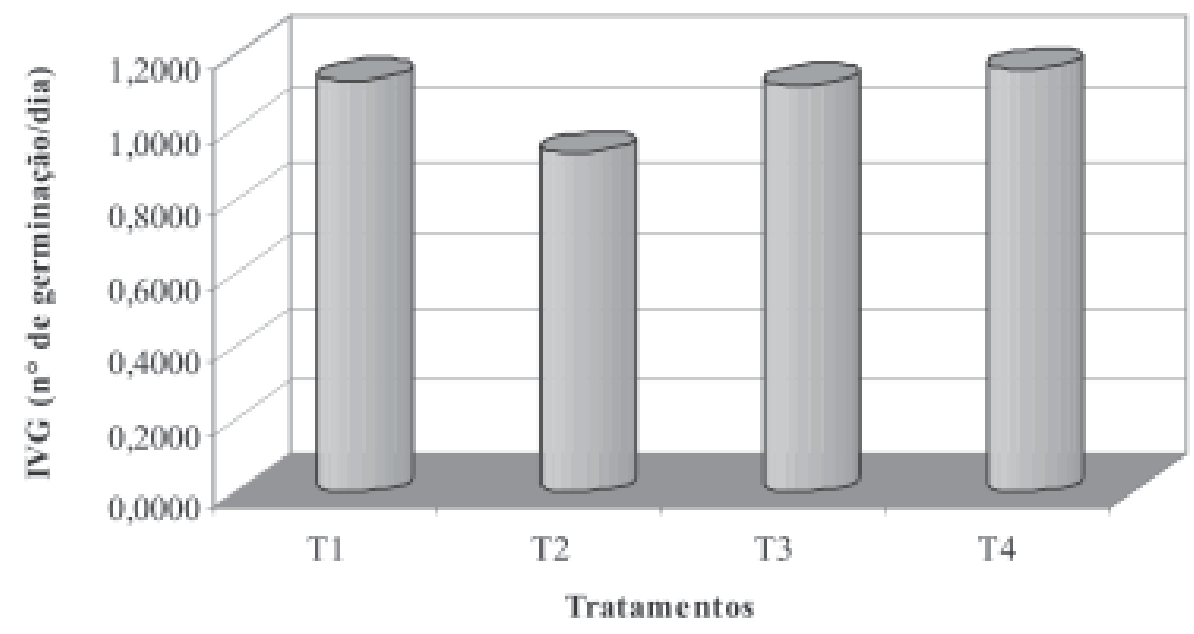

FIGURA 2 - Índice de velocidade de germinação médio de Araucaria angustifolia (Bert.) Kuntze para as diferentes concentrações do extrato de Merostachys multiramea Hackel

Figure 2 - Average of germination speed index of Araucaria angustifolia (Bert.) Kuntze to different concentrations of the Merostachys multiramea Hackel extract

A análise de variância mostrou que não houve diferença estatisticamente significativa, a 95\% de probabilidade, no índice de velocidade de germinação de sementes de Araucaria angustifolia (Bert.) Kuntze, tratadas com diferentes concentrações do extrato de Merostachys multiramea Hackel (TABELA 5).

TABELA 5 - Análise de variância aplicada aos valores de índice de velocidade de germinação Table 5 - Analysis of variance applied to values of germination speed index

\begin{tabular}{lccccc}
\hline Fonte de Variação & GL & SQ & QM & F & F critico \\
\hline Tratamentos & 3 & 0,16 & 0,05 & $0,71^{\mathrm{NS}}$ & 3,24 \\
Erro Experimental & 16 & 1,22 & 0,08 & & \\
\hline Total & 19 & 1,38 & & & \\
\hline
\end{tabular}

\section{CONCLUSÕES}

A partir dos resultados obtidos no presente estudo, é possível concluir que:

- o extrato preparado com folhas verdes da Merostachys multiramea Hackel (Taquaracomum) não influenciou significativamente na percentagem de germinação e na sua velocidade;

- o tratamento testemunha, no qual se utilizou somente água, apresentou maior número de sementes germinadas, seguido do tratamento 2,5\%. Entretanto, o tratamento onde a concentração de extrato era de $10 \%$ resultou em uma taxa de germinação maior que o tratamento com concentração de $5 \%$, evidenciando não haver influência alelopática 
quando aplicadas diferentes concentrações de extrato de Merostachys multiramea Hackel. Essa mesma lógica foi observada ao avaliar a velocidade de germinação, onde tratamento com a concentração $2,5 \%$ resultou em valores mais altos para essa variável. Contudo o tratamento com maior concentração do extrato $(10 \%)$ apresentou germinação mais lenta, evidenciando uma possível diferença significativa para essa variável ao serem utilizadas concentrações mais altas do que as avaliadas no presente estudo;

- os resultados mostraram que não houve influência significativa do extrato de Merostachys multiramea Hackel nas variáveis avaliadas em níveis de concentração $0 \%$, $2,5 \%, 5 \%$ e $10 \%$.

\section{REFERÊNCIAS}

CARVALHO, P. E. R. Espécies florestais brasileiras. Brasília: Embrapa Florestas, 2003. 1039 p.

CASTELLA, P. R.; BRITEZ, R. M. A floresta com araucária no Paraná: conservação e diagnóstico dos remanescentes florestais. Brasília: Fundação de Pesquisas Florestais do Paraná. Brasília: Ministério do Meio Ambiente, 2004. 236 p.

FERREIRA, A. G.; AQUILA, M. E. A. Alelopatia: uma área emergente da ecofisiologia. Revista Brasileira de Fisiologia Vegetal, v. 12, p. 175-204, 2000. Edição Especial.

GUILHERME, F. A. G. Efeitos do regime de inundação e de bambus na dinâmica da comunidade arbórea de um fragmento de floresta semidecídua no sul de Minas Gerais. 1999. 73 f. Dissertação (Mestrado) - Universidade Federal de Lavras, Lavras, 1999.

LIMA, E. C. Qualidade multitemporal da paisagem: estudo de caso na Floresta Ombrófila Mista em General Carneiro - PR. 2003. 145 f. Dissertação (Mestrado) - Universidade Federal do Paraná, Curitiba, 2003.

MAACK, R. Geografia física do Estado do Paraná. Curitiba: José Olympio, 1968. 450 p.

MEDEIROS, A. R. M. Alelopatia: importância e suas aplicações. Horti Sul, v. 1, n. 3, p. 27-32, 1990.

PIÑA-RODRIGUEZ, F. C. M.; LOPES, B. M. Potencial alelopático de Mimosa caesalpinaefolia Benth sobre sementes de Tabebuia alba (Cham.) Sandw. Floresta e Ambiente, Rio de Janeiro, v. 8, n. 1, p. 130136, 2001.

SANQUETTA, C. R. et al. Sobrevivência de mudas de Araucaria angustifolia Bert. O. Ktze. plantadas em um experimento de controle de taquaras (Bambusoideae) no sul do Paraná, Brasil. Floresta, Curitiba, v. 35, n. 1, p. 127-135, 2005.

RICE, E. L. Allelopathy. New York: Academic Press, 1974.

RIZVI, S. J. H. et al. discipline called allelopathy. In: RIZVI, S. J. H.; RIZVI H. (Ed.). Allelopathy: Basic and applied aspects. London: Chapman \& Hall, 1992. p. 1-10.

Recebido em: 07/05/2006

Received in: 05/07/2006

Aprovado em: 30/09/2006

Accepted in: 09/30/2006 